\title{
DIABETES MELLITUS NA INFÂNCIA: REPERCUSSÕES NO COTIDIANO DA CRIANÇA E DE SUA FAMÍLIA
}

Calíope Pilger ${ }^{1}$, Isabella Schroeder Abreu ${ }^{2}$

\begin{abstract}
RESUMO: O presente estudo teve como objetivo entender que transformações ocorrem no contexto familiar, na visão materna, em face do surgimento da diabete em seu filho. A pesquisa foi qualitativa, realizada no município de Guarapuava (PR), com sete mães de crianças portadoras de diabetes. As mães foram escolhidas aleatoriamente, sendo todas pertencentes aos Centro Integrado de Atendimento do município. A coleta dos dados foi realizada através de entrevista aberta, a qual foi gravada e posteriormente transcrita na íntegra. Os dados foram analisados mediante o método Análise Temática. Concluiu-se que, após o diagnóstico da doença de seus filhos, as mães passaram a ter novas incumbências, modificando seus hábitos alimentares, aprendendo como fazer o regime de tratamento, o regime alimentar, conhecendo a doença e aprendendo a lidar com seus incômodos físicos e sociais. A partir dos resultados encontrados, observou-se a importância da realização de prevenção das complicações da doença e de intervenções visando a promoção da qualidade da relação dessas díades e de suas famílias.
\end{abstract}

PALAVRAS-CHAVE: Diabetes mellitus; Família; Criança

\section{DIABETES MELLITUS IN CHILDHOOD: REPERCUSSIONS IN THE DAILY LIFE OF THE CHILD AND HIS/HER FAMILY}

\begin{abstract}
The present study aimed to understand what changes may occur in the family context - maternal view - facing diabetes diagnosis in her child. This qualitative research was held in Guarapuava municipality/ Brazil with 7 (seven) mothers of diabetic children. Mothers were randomly selected and attended the Integrated Care Center of the municipality. Data collection was carried out by means of an open interview which was recorded and further fully transcribed. Data were analyzed by Thematic Analysis. It was concluded that, after diagnosis of their children's disease, mothers had to undertake new tasks, modifying diet habits, learning to deal with the treatment routine, dieting, getting to know the disease and learning to cope with its physical and social inconveniences. From the results, it was observed the importance of prevention from the disease complications and interventions aiming to promote the quality of relation between mothers/children and their families.
\end{abstract}

KEY WORDS: Diabetes mellitus; Family; Child

\section{DIABETES MELLITUS EN EL INFANTE: REPECUSIONES EN EL COTIDIANO DEL INFANTE Y DE SU FAMILIA}

RESUMEN: Este estudio tuvo como objetivo entender las transformaciones que ocurren en el contexto familiar en la visión materna frente al surgimiento de la diabetes en su hijo. La investigación fue cualitativa y realizada en el municipio de Guarapuava/PR, con siete madres de niños portadores de diabetes. Las madres fueron escogidas de modo aleatorio, siendo todas pertenecentes al Centro Integrado de Atendimiento de municipio. La colecta dos datos fue realizada por medio de entrevista abierta, la cual fue grabada y, después, transcrita integralmente. Los datos fueron analizados por el método Análisis Temático. Se concluyó que, después del diagnóstico de la enfermedad de sus hijos, las madres pasan a tener nuevas incumbencias, cambiando sus hábitos alimentares, aprendiendo cómo hacer el régimen de tratamiento, el régimen alimentar, conociendo la enfermedad y aprendiendo a lidiar con sus incómodos físicos, sociales. Por medio de los resultados encontrados, se ha observado la importancia de la realización de prevención de las complicaciones de la enfermedad y de intervenciones con el obgetivo de promover cualidade de relación de esas pareja y de sus familias.

PALABRAS CLAVE: Diabetes mellitus; Família; Niño.

${ }^{1}$ Acadêmica de Enfermagem da Universidade Estadual do Centro-Oeste - UNICENTRO.
${ }^{2}$ Enfermeira. Mestre. Professora. Departamento de Enfermagem da UNICENTRO.

Autor correspondente:

Calíope Pilger

Rua Osório de Almeida Takes, 517, bl. 5 ap.31 - 85162000 - Guarapuava-PR

Recebido: 20/08/07

E-mail: caliopepilger@hotmail.com 


\section{INTRODUÇÃO}

O desenvolvimento científico e tecnológico tem possibilitado o diagnóstico precoce das doenças e a terapêutica adequada permite, muitas vezes, o controle de sua evolução e cura. Mesmo com esses avanços, algumas doenças, especialmente as crônicas, promovem alterações orgânicas, emocionais e sociais que exigem constantes cuidados e adaptação ${ }^{(1) .}$

As doenças crônicas, consideradas incuráveis e permanentes, exigem que o indivíduo ressignifique sua existência, adaptando-se às limitações, frustrações e perdas. Essas mudanças serão definidas pelo tipo de doença, maneira que se manifesta e como segue o seu curso, além do significado que o paciente e a família atribuem ao evento.

Quando nos referimos à criança, o esperado é que ela viva situações de saúde para crescer e desenvolver-se dentro dos limites da normalidade, porém, quando nos defrontamos com ela na condição de doente, como todo ser humano, tem seu comportamento modificado. Sua reação diante dessa experiência desconhecida, a doença, pode lhe trazer sentimentos de culpa, medo, angústia, depressão e apatia e ameaçar a rotina do seu dia-a-dia ${ }^{(2)}$.

O diabetes mellito insulino-dependente (IDDM, ou tipo I) é uma doença crônica relativamente comum $\mathrm{e}$, freqüentemente, se apresenta na infância. O IDDM afeta aproximadamente uma em cada quinhentas pessoas abaixo dos vinte (20) anos de idade, com uma incidência de dez por cem mil (100.000) pessoas/ano nesta faixa etária. Embora a incidência seja máxima aos doze anos de idade, o IDDM pode se apresentar em qualquer idade e não existe predileção por sexo. $\mathrm{O}$ diabetes é a terceira causa principal de morte por doença, principalmente devido à alta taxa de doença coronariana entre pessoas com diabetes ${ }^{(3)}$.

Devido às grandes complicações e problemas que o diabetes traz para a vida da criança e de sua família, cabe aos profissionais de saúde estar atentos na identificação das pessoas com risco para esta doença e intensificar as ações para promover o seu controle, entre os já diagnosticados. Um estudo demonstrou que pessoas com diabetes mellitus que tiveram apoio adequado de amigos e familiares aderiram melhor às condutas de auto-cuidado. Os autores ainda relatam que avaliar os meios de apoio do paciente pode ajudar a identificar as suas necessidades de assistência, no propósito de evitar as complicações de longo prazo ${ }^{(4)}$.

Considerando-se que normalmente a mãe é a pessoa que está mais presente e próxima à criança, durante o processo de seu tratamento e, ainda, que um trabalho sobre esse tema poderá contribuir para um melhor entendimento das implicações da diabete mellitus na infância e as repercussões desta doença para a criança no seu dia-a-dia, neste trabalho objetivou-se entender que transformações ocorrem no contexto familiar na visão materna, em face do surgimento da diabetes em seu filho.

\section{REVISÃO DE LITERATURA}

\section{Doenças crônicas na infância}

O diabetes é uma doença crônica, grave, de evolução lenta e progressiva, que necessita de tratamento intensivo e uma orientação adequada que permita prevenir ou retardar as complicações agudas e crônicas da doença. Para que isso aconteça, é preciso um envolvimento harmonioso e contínuo de pacientes, família e profissionais de saúde, na busca de se atingir o equilíbrio biológico, psíquico e social do indivíduo ${ }^{(5)}$.

As doenças crônicas têm sido definidas como perturbações de saúde que persistem por longos períodos de tempo, podendo se estender ao longo de toda vida. Ainda que tais doenças possam ser manejadas ou controladas no intuito de diminuir o sofrimento e melhorar a qualidade de vida dos doentes, na maioria dos casos,porém, não são completamente curáveis ${ }^{(6)}$.

A doença crônica na infância se caracteriza por ter um curso demorado, ser progressiva, apresenta riscos de prejuízos no desenvolvimento físico e mental da criança e necessitar de tratamentos prolongados ${ }^{(6)}$.

No Brasil, assim como em muitas outras localidades, o diabetes mellitus está sendo reconhecido como um importante problema de saúde pública, principalmente nos países em desenvolvimento, em que ele tem representado de 30 a $40 \%$ das causas de morbidade entre adultos ${ }^{(3)}$. Esta doença também vem alcançando um espaço cada vez maior na literatura, com o aumento de pesquisas nesta área, representando, assim, uma doença crônica de grande importância.

$\mathrm{O}$ diabetes tipo I ou insulino-dependente ocorre em pacientes jovens, que passam a necessitar de injeções diárias de insulina para se manter em boas condições. Ao contrário do diabetes tipo II (de início na idade adulta), o problema fundamental no DMID é a deficiência do hormônio - insulina. Esta perda de secreção de insulina é, geralmente, mediada por uma destruição auto-imune das células das ilhotas 
produtoras de insulina do pâncreas. Como resultado, o tratamento para diabetes tipo I deve incluir a reposição parenteral de insulina ${ }^{(7)}$.

Em um estudo sobre a prevalência do diabetes mellitus no Brasil, concluiu-se que devem existir cerca de 4 milhões e 500 mil diabéticos no país, dos quais aproximadamente $450 \mathrm{mil} \mathrm{em}$ uso de insulina (todos aqueles com menos de 30 anos de idade e 7,9\% dos demais $)^{(8)}$.

\section{Diabetes mellitus na infância: repercussões para a criança e seus familiares}

Em particular, o diabetes mellitus requer da criança e adolescente diabético, das famílias e dos profissionais de saúde, esforços conjuntos para que os portadores atinjam um bom controle metabólico, a fim de minimizar as complicações advindas a longo prazo ${ }^{(9)}$. Estes esforços devem ser direcionados para ajudar a criança e o adolescente a administrar o complexo regime de insulina, dieta e exercícios, a fim de manter os níveis de glicose sangüínea dentro dos limites de normalidade, proporcionando-lhes qualidade de vida.

A complexidade do diabetes - o seu tratamento, o uso e o acesso às tecnologias - influencia a trajetória da doença. Assim, algumas fases da doença podem ser previsíveis e outras, incertas, porém todas causam impactos e danos à criança e à família. Cada fase exige tarefas próprias, requerendo delas força, mudanças de comportamento, de atitude e readaptações ${ }^{(10)}$.

A educação é parte essencial no controle do diabetes e consiste em um processo contínuo de alteração de hábitos de vida que requer tempo, espaço, planejamento, material didático e profissionais capacitados. Apenas seguir a prescrição médica corretamente, aplicando a dose e o tipo de insulina no momento certo, não é o suficiente para a melhoria da qualidade de vida desses indivíduos ${ }^{(11)}$.

O comportamento da criança depende diretamente de como os pais lidam com sua condição. Pais que têm dificuldade em aceitar o diabetes do filho e que se comportam com a criança diabética de forma a deixar transparecer essa dificuldade podem acabar provocando nela o isolamento. A criança, mediante as atitudes dos pais, confirmam que são diferentes em relação às outras e, por isso, se isolam ${ }^{(12)}$.

O número de crianças diabéticas tem sido cada vez mais freqüente nos tempos atuais. O papel da família é de fundamental importância para manter o equilíbrio emocional da criança, que já se encontra demasiadamente abalado. A maneira como a família lida com a situação influenciará a criança na aceitação ou negação da doença. É melhor que ela compreenda suas limitações, do que se revoltar com seu estado; para tanto, é necessário que os pais sejam compreensivos, sem superproteger. $\mathrm{Na}$ medida do possível, eles devem evitar acentuar as diferenças entre a criança e os outros integrantes da família. Isso fará com que a criança diabética sinta-se discriminada, reforçando suas carências afetivas ${ }^{(13)}$. Como estamos observando, o equilíbrio entre independência e dependência da criança doente necessita ser abordado dentro do contexto familiar. Para administrar os cuidados que uma doença crônica exige, tal como o diabetes em crianças e adolescentes, necessita-se de uma abordagem para o cuidado através de uma equipe multiprofissional, tendo a criança, o adolescente e a família como foco central deste cuidado ${ }^{(5)}$.

\section{MATERIAL E MÉTODOS}

Trata-se de um estudo de abordagem qualitativa, realizado em 2006, do qual fizeram parte sete mães de crianças portadoras de diabetes mellitus há pelo menos seis meses. A idade das crianças variou entre 5 a 12 anos e as mesmas foram escolhidas aleatoriamente. Adotou-se como critério de inclusão que cada uma das mães deveria ter seu filho cadastrado em um CIA (Centro de Saúde Integrada) do município de Guarapuava-PR. A coleta de dados foi realizada na residência dos sujeitos do estudo, após um contato prévio com a enfermeira responsável pela unidade de saúde do bairro escolhido.

Para obtenção dos dados foi utilizada uma entrevista aberta, que teve a seguinte questão norteadora: "Fale sobre a doença de seu filho e quais as repercussões desta em suas vidas". Esta entrevista foi gravada e posteriormente transcrita na íntegra e o período de coleta de dados foi de março a julho de 2006.

A realização deste trabalho foi autorizada pela Secretaria Municipal de Saúde do município de Guarapuava e o projeto de pesquisa foi aprovado pelo Comitê de Ética e Pesquisa da Universidade Estadual do Centro-Oeste - UNICENTRO sob o protocolo $\mathrm{n}^{\mathrm{o}} .18 / 2006$. Todos os participantes assinaram o Termo de Consentimento Livre e Esclarecido, atendendo aos preceitos da Resolução 196/96.

Para viabilizar o sigilo, foram utilizados nomes de ervas como codinomes para as depoentes da pesquisa. Estes foram atribuídos aleatoriamente, sem um critério 
específico. São elas: Hortelã, Cidreira, Camomila, Erva Doce, Melissa, Laranjeira e Endro.

Utilizou-se a Análise Temática para organização e análise dos dados, em que se buscou-se os núcleos de sentido que compõem a comunicação, cuja freqüência significou alguma coisa para o objetivo analítico visado.

\section{APRESENTAÇÃO E ANÁLISE DAS CATEGORIAS}

Após conhecer as percepções das mães mediante os dados obtidos, os mesmos foram organizados em 10 categorias: preocupação, dificuldade de aceitação, medo do desconhecido, negação, medo das consequiências trazidas pela doença, mudança de rotinas/hábitos, medo da morte, autocuidado, sofrimento e esperança de cura.

\section{Preocupação}

Do ponto de vista tradicional, no diagnóstico de uma doença a preocupação é o primeiro sentimento demonstrado, pois a doença constitui uma solução de continuidade violenta entre o viver anterior e o presente, tornando o futuro incerto. Sabemos que estas doenças são permanentes, levando o indivíduo a incorporar a doença no seu processo de vida, passando a conviver com a condição de doença crônica ${ }^{(1)}$. A preocupação é um sentimento bastante intenso após o aparecimento da doença e se evidencia no depoimento de Melissa:

[...] foi como me tirassem o chão, pois como só tenho ela e sabia que era uma coisa que não tem cura ainda e que teria que ser pelo resto da vida (Melissa).

Na formação do significado da doença, muitos sentimentos e reações podem surgir no paciente e seus familiares: culpa, desespero, raiva, frustração, inconformismo, incerteza, dúvidas, medo, negação por falta de recursos, sensação de impotência, desânimo, ameaça à integridade do paciente e sistema ${ }^{(14)}$.

\section{Dificuldade de aceitação}

A família, desde o início dos sintomas até a definição do diagnóstico e tratamento, vivencia uma fase de crise, caracterizada por um período de desestruturação e incertezas, tendo que aprender a lidar com sintomas, procedimentos diagnósticos e terapêuticos, para assim reorganizarem suas vidas. A não aceitação da doença é um sentimento gerado a partir destas experiências vividas, o que se observa nos depoimentos a seguir:

[...] faz uns dois anos que eu aceitei. Ficou muito mais fácil, porque eu consigo falar, sem chorar e não é para todo mundo que eu conto, porque ainda me dói [...] ( Melissa).

[...] na hora dá um caos na família, meu Deus! A gente se pergunta como foi acontecer isso na família, mas sei lá, a gente tem que se conformar [...] (Laranjeira).

As experiências de familiares de crianças com uma doença crônica podem manifestar-se de diferentes formas, podendo apresentar problemas para dormir, hipertensão e palpitações após a descoberta da enfermidade do filho, além de referirem impacto emocional intenso e sentimentos de preocupação, não aceitação, medo e responsabilidade ${ }^{(9)}$.

\section{Medo do desconhecido}

Os sentimentos mais comuns para o enfrentamento da doença são sentimentos desconfortáveis como: culpa, medo e ansiedade. Estes sentimentos são formas de enfrentamento significativo de situações que ameaçam o indivíduo, o que se observa na fala a seguir:

Eu tenho medo desta doença porque ela é traiçoeira. Tem horas que está muito alta, daí já está baixa. Não tem controle dela. É muito traiçoeira [...] (Camomila).

O enfrentamento é entendido como um processo dinâmico, pelo qual o indivíduo trabalha as questões de relacionamento da pessoa no seu contexto, sendo avaliadas em função do estresse que causam e da emoção que geram ${ }^{(15)}$.

O "medo do desconhecido" gera dificuldades de enfrentamento, como relatam Hortelã e Endro:

Não explicaram prá gente o que era aquela doença. Eu não sabia o que era. Nossa! Foi muito susto, surpresa [...] (Hortelã).

[...] no começo, quando ia fazer a insulina nele, eu tremia, mas agora não [...] (Laranjeira). 
Considerando ainda a diversidade de problemas enfrentados pelos pais, o diabetes pode ter efeito profundo na dinâmica familiar, situação esta observada quando os pais assumem a administração de injeções de insulina, pois ficam em conflito e acabam não tendo outra opção a não ser magoar o filho ${ }^{(16)}$.

\section{Negação}

O sentimento mais comum neste momento inicial de descoberta da doença é o de negação. A negação ocorre mais no início do processo da doença crônica, dos estados graves de saúde e de estados terminais, mas pode voltar em outros momentos, sendo este um período que ajuda o paciente a se recuperar do choque inicial provocado pela notícia da doença ${ }^{(17)}$.

[...] eu não queria aceitar, mas fazer o quê? É necessário para poder ter forças para agüentar [...] Eu não falava nos primeiros anos. Não conseguia falar do assunto, mas agora já consigo. Antes, machucava muito [...] (Camomila).

Na relato anterior, evidenciamos que o simples fato de "comentar" sobre a doença do filho já causava sofrimento, evitando-se então falar sobre o assunto, fato este que demonstra a negação à doença.

\section{Medo das conseqüências trazidas pela doença}

Tanto os pacientes quanto seus familiares possuem dificuldades em conviver com a doença sendo propensos a sentimentos de impotência, desânimo e permanente sensação de ameaça à integridade corporal do paciente ${ }^{(18)}$.

[...] eu tenho muito medo das conseqüências que pode dar isso, que não me deixa dormir direito. Eu nunca mais dormi direito na minha vida. Fico nervosa, me bato, me acordo [...] (Cidreira).

[...] a gente ouve os outros falar e fica com medo, porque o problema da doença não é agora é daqui uns vinte anos e se agente não tomar cuidado começa aparecer os sintomas [...] (Erva-doce).

Outro aspecto importante é o significado que é atribuído à doença. A doença crônica é aceita a partir de um significado que lhe é atribuído e que nomeia tal experiência.Todos os membros vivenciam o processo de adoecer com os recursos que lhe são disponíveis, portanto, diferentes significados surgem de acordo com a história pessoal de cada membro ${ }^{(19)}$ :

[...] o meu maior medo é de dar problema nos rins dele. Deus me livre! Ele ter de fazer hemodiálise! [...] (Erva Doce).

Estudos demonstram que o diabetes mellitus produz, concomitantemente, alterações em vários aparelhos e sistemas nos diabéticos não controlados que são suscetíveis a complicações altamente incapacitantes como: cegueira, insuficiência renal crônica e doenças cardiovasculares, que causam grande dificuldade para a realização diária das atividades produtivas ${ }^{(11)}$.

\section{Mudança de rotinas/hábitos}

A doença crônica pode ser vista como um estressor que afeta o desenvolvimento normal da criança e também atinge as relações sociais dentro do sistema familiar. A rotina da família muda com constantes visitas ao médico, medicações e hospitalizações ${ }^{(9)}$. A modificação no cotidiano familiar, principalmente as mudanças relacionadas aos hábitos alimentares, fica evidente na seguinte fala:

[...] Porque nós tivemos que mudar todos nossos hábitos alimentares, porque gostávamos muito de massa, sorvete e a gente tem de manerar [...] Sempre trabalhei fora, tinha dois empregos, até pensei em largar, imagine prá mim que nunca fiquei em casa [...] (Melissa).

As limitações impostas pela doença crônica afetam também a família, que precisa se adaptar às necessidades do membro doente. Para isso, ela utiliza novos recursos de enfrentamento. Há uma quebra do equilíbrio dinâmico familiar diante do novo evento. As mudanças que ela acarretará e as adaptações que essa família realizará dependerão dos recursos de que dispõe, de como o evento começou e o significado que atribui ao acontecimento. $\mathrm{O}$ equilíbrio é buscado através das novas adaptações ${ }^{(20)}$.

\section{Medo da morte}

Quando uma criança morre ou é acometida por uma doença grave, é como se o processo de ciclo de vida estivesse fora de ordem. Em relação às 
responsabilidades familiares, o impacto não gera consequiências. O impacto maior é emocional, pois é nas crianças que os pais projetam sonhos e expectativas. Um dos pais precisa estar disponível para cuidados em tempo integral, tendo que parar de trabalhar fora e havendo perda de um salário, ou tendo que abrir mão de desenvolver suas atividades. Os pais podem ter sentimentos oscilantes de luto durante as crises. Esse luto decorre do fato de não terem gerado uma criança perfeita, pela incerteza em relação à vida, morte e futuro e o impacto disso na rotina familiar ${ }^{(21)}$. A família pode não saber como agir, tendo atitudes ora de aproximação com o doente, ora de isolamento emocional. Se o luto é vivido de forma antecipatória, a família pode isentar o doente de responsabilidades e atividades, isolando-o do convívio. A expectativa da perda está presente e é clara para todos os membros, fazendo com que mobilizem recursos para lidar com isso $^{(14)}$. No relato de Cidreira isto pode ser evidenciado:

[...] eu tenho medo dele morrer dormindo. A verdade é essa, subir demais ou abaixar demais, mas meu medo maior é dele morrer [...] (Cidreira).

Toda a limitação causada pela doença, as seqüelas geradas e as modificações na vida do paciente podem ser vividos como morte. As perdas sociais, biológicas e psíquicas podem iniciar o processo de luto antes mesmo da morte propriamente dita ${ }^{(22)}$.

\section{Auto-cuidado}

A doença crônica impõe modificações na vida da criança/adolescente e sua família, exigindo readaptações frente à nova situação e estratégias de enfrentamento ${ }^{(10)}$.

Em relação à insulina e, em particular, à monitoração de glicose no sangue e urina, é recomendado que os pais e a equipe de saúde favoreçam oportunidades de aprendizagem para que a criança possa desenvolver habilidades para autoaplicação de insulina e controle domiciliar visando sua independência ${ }^{(16)}$.

Este fato fica evidente nas falas de Camomila e Erva-doce, em que relatam sobre a experiência dos próprios filhos em auto-cuidar-se:

\section{[...] comprei o aparelho e agora ela mesma aplica a} insulina. Faz os testes sozinha [...] (Erva-doce).
[...] os meus dois filhos se aplicam insulina. $O$ problema é meu filho que não quer aplicar na barriga [...] (Camomila).

A existência de sintomas dolorosos associados à doença e as constantes avaliações e tratamento podem alterar o funcionamento físico e mental da criança, bem como sua interação com o meio ambiente ${ }^{(24)}$. Frente às necessidades de conviver com a doença crônica, que exige retornos e hospitalizações frequientes, a criança e o adolescente passam a se familiarizar com os procedimentos e nomes dos medicamentos, apropriandose de um vocabulário técnico ${ }^{(1)}$.

\section{Sofrimento}

As repetidas visitas ao médico e a necessidade de assegurar que as medicações sejam dadas em horas específicas são fatores que potencializam o estresse dessas mães e pais com um filho com doença crônica. Eles sentem seus papéis parentais muito mais exigidos do que situações em que a criança é saudável:

[...] o que mais sofro é pensar que a minha filha já ficou 4 vezes internada na UTI. Isso é um sofrimento muito grande. Pensar que pode ser internada novamente! Também sofro por ela não querer se ajudar. Ela é muito revoltada e isso me deixa preocupada e nervosa [...] (Camomila).

\section{Esperança de cura}

Existem maneiras para o enfrentamento da condição crônica de saúde, como: procurar informações, adquirir habilidades, usar recursos como monitorização e adesão à terapia e incorporação da nova situação ao estilo de vida familiar. Quanto ao enfrentamento focalizado nas emoções e sentimentos de incerteza, ambigüidades e insegurança recomenda-se a utilização de estratégias como: explicações para o que está acontecendo, considerando as causas e resultados da condição de doença crônica que está vivenciando, utilizar mecanismos de defesa como manter esperança, manter processo de comunicação e de relacionamento para aceitar, oferecer e recusar suporte ${ }^{(15)}$.

[...] e agora, eu procuro viver a vida. Fazer o quê? Tenho muita fé que logo achem a cura [...] (Melissa).

[...] eu acredito que vai ter cura ainda. Só pedir 
prá Deus, porque para Deus nada é impossível. É só ter fé [...] (Hortelã).

Nesses depoimentos se observa a "esperança da cura", reforçando que este sentimento é uma forma de suporte para se adaptar às novas estruturas que se remodelam nas suas vidas.

\section{CONSIDERAÇÕES FINAIS}

A escolha da abordagem qualitativa como opção metodológica para a realização deste estudo permitiu compreender a realidade cotidiana das mães que possuem filhos com diabetes tipo I, além de apreender os significados dados à doença crônica infantil.

$\mathrm{Na}$ realização desta pesquisa surgiram dificuldades relacionadas com a amostra do estudo que se constituiu somente de sete mães, sendo que o número de CIAs e a amostra esperada era de 10 mães.

$\mathrm{Na}$ análise dos dados pôde-se evidenciar que as repercussões causadas após diagnóstico de diabetes mellitus foram tanto positivas quanto negativas e implicaram no estabelecimento de uma nova rotina para o sistema familiar, o que se observou nas 10 categorias encontradas.

Acredita-se que o apoio profissional é importante para que se estabeleça um novo funcionamento nas relações familiares. Pensando no contato com uma rede de apoio, além do auxílio psicoterapêutico, é necessário que a família tenha como referência a equipe de saúde, para mantê-la informada a respeito da doença e sobre cuidados com a criança. Estando amparada e informada, a família se instrumentalista para auxiliar o paciente.

$\mathrm{O}$ auxílio às famílias de doentes crônicos e também ao próprio doente é importante, principalmente quando encontram dificuldades para se adaptar. $\mathrm{Na}$ assistência à criança e ao adolescente, o cuidado deve contemplar não somente os aspectos técnicos, mas também suas necessidades físicas, emocionais e sociais e, através de estratégias, minimizar o estresse ocasionado pelas intervenções. Acredita-se que isto não só refletirá positivamente na aderência da criança e da família ao tratamento médico, mas também no bemestar de todos os envolvidos.

\section{REFERÊNCIAS}

1 Roland JS. Doença crônica e o ciclo de vida familiar. In: Carter S, Goldrinle M. As mudanças no ciclo de vida familiar. Porto Alegre: Artes Médicas; 1995. p.372-92.
2 Huerta EPN. Brinquedo no hospital. Rev Esc Enferm USP. 1990;24(3):319-28.

3 Hoett JJ. Uma esperança para os diabéticos. Saúde do Mundo. 1991:12(5):4-5.

4 Pace AE, Nunes PD, Ochoa Vigo K. O conhecimento dos familiares acerca da problemática do portador de diabetes mellitus. Rev Latino-am Enferm. 2003;11(3):312-9.

5 Faria S, Martins DV. Colônia de ferias de 1 dia: experiência com atividades educativas em situações do cotidiano do diabético. In: XI Congresso da ALAD; 2001.p. 165 .

6 Perrin EC, Gerrity S. Desenvolviment of children with chronic disease. Crianças portadoras de enfermidades crônicas. Pediatr Clin North Am. 1984;21(1):347.

7 Rudolph AM, Kamel RK. Rudolph: Princípios de Pediatria. São Paulo: Roca; 1997.

8 Sociedade Brasileira de Diabetes. Tudo sobre diabetes; 2006. [acesso em 2006 Jun 15]. Disponível em: http:// www.diabetes.org.br/diabetes/index.php.

9 Piccinin CA. A doença crônica orgânica na infância e as práticas educativas maternas. Est Psicol. 2002;9(3):12-3.

10 Vieira MA, Lima RAG. Crianças e adolescentes com doença crônica: convivendo com mudanças. Rev Latino-am Enferm. 2002; 10(4):552-60.

11 Pousada JMDC, Britto MMS. Tratamento do diabetes mellito tipo 1. In: Coronho V, Petroianu A. Tratado de endocrinologia e metabologia e cirurgia endócrina; 2001 p. $935-8$

12 Ribeiro PG. Crianças e adultos têm reação diversa ao diabetes. [acesso em 2005 Nov 15] Disponível em: http://www.diabetesnoscuidamos.com.br/ materia.asp?id=823.

13 Valcapelli A. Metafísica da saúde [acesso em 2006 Mar 16]. Disponível em: http://www.valcapelli.com/ pgmaterias/diabetes.

14 Messa A. O impacto da doença crônica na família [acesso em 2006 Fev 28]. Disponível em: < http:// www.psicologia.org.br/internacional/pscl49.htm.

15 Fonseca AS. As questões familiares e a criança e o adolescente com doença crônica: um estudo de revisão bibliográfica. Nursing. 2005;85(8):21. 
16 Zanetti ML, Mendes IAC. Análise das dificuldades relacionadas às atividades diárias de crianças e adolescentes com diabetes mellitus tipo 1: depoimento de mães. Rev Latino-am Enferm. 2001;9(6):25-30.

17 Kubler Ross E. Sobre a morte e o morrer. São Paulo: Martins Fontes; 1996.

18 Santos CT. O enfrentamento das incapacidades e perdas geradas pela doença crônica: um estudo de portadores de insuficiência renal crônica em hemodiálise [dissertação]. São Paulo(SP): Universidade São Marcos; 1997.

19 Radley A. Word of illness: Biographical and cultural perspectives on health and disease. London: Routledge; 1995.

20 Tetelbom M. A criança com doença crônica e sua família: a importância da avaliação psicissocial. J Ped. 1993;69(1):5-11.

21 Bromberg MHPF. Vida e morte: laços de existência. São Paulo: Casa do psicólogo; 1996.

22 Vieira MA, Lima RAG. Crianças e adolescentes com doença crônica: convivendo com mudanças. Rev Latino-am Enferm. 2002;10(4): 552-60.

23 Bradford R. Children, families and chronic didease. Londres: Routledge; 1997. 